Article

\title{
Co-Precipitated Ni-Mg-Al Hydrotalcite-Derived Catalyst Promoted with Vanadium for $\mathrm{CO}_{2}$ Methanation
}

\author{
Paulina Summa 1,2,*, Katarzyna Świrk ${ }^{3} \mathbb{D}$, Dominik Wierzbicki ${ }^{2,4}$, Monika Motak ${ }^{2}$ (D) Ivo Alxneit ${ }^{4}$, \\ Magnus Rønning ${ }^{3}$ (iD) and Patrick Da Costa $1, *$ (D)
}

1 Institut Jean Le Rond d'Alembert, Sorbonne Université, CNRS UMR 7190, 78210 Saint-Cyr-L'Ecole, France

2 Faculty of Energy and Fuels, AGH University of Science and Technology, 30-059 Kraków, Poland; dominik.wierzbicki@psi.ch (D.W.); motakm@agh.edu.pl (M.M.)

3 Department of Chemical Engineering, Norwegian University of Science and Technology (NTNU), 7491 Trondheim, Norway; katarzyna.swirk@ntnu.no (K.Ś.); magnus.ronning@ntnu.no (M.R.)

4 Paul Scherrer Institut (PSI), 5232 Villigen, Switzerland; ivo.alxneit@psi.ch

* Correspondence: summa@agh.edu.pl (P.S.); patrick.da_costa@sorbonne-universite.fr (P.D.C.)

check for

updates

Citation: Summa, P.; Świrk, K.;

Wierzbicki, D.; Motak, M.; Alxneit, I.;

Rønning, M.; Da Costa, P.

Co-Precipitated Ni-Mg-Al

Hydrotalcite-Derived Catalyst

Promoted with Vanadium for $\mathrm{CO}_{2}$

Methanation. Molecules 2021, 26, 6506.

https://doi.org/10.3390/

molecules26216506

Academic Editor: Adriana Urda

Received: 22 September 2021

Accepted: 25 October 2021

Published: 28 October 2021

Publisher's Note: MDPI stays neutral with regard to jurisdictional claims in published maps and institutional affiliations.

Copyright: (c) 2021 by the authors. Licensee MDPI, Basel, Switzerland. This article is an open access article distributed under the terms and conditions of the Creative Commons Attribution (CC BY) license (https:/ / creativecommons.org/licenses/by/ $4.0 /)$.

\begin{abstract}
Co-precipitated $\mathrm{Ni}-\mathrm{Mg}$-Al hydrotalcite-derived catalyst promoted with vanadium were synthesized with different $\mathrm{V}$ loadings (0-4 wt\%) and studied in $\mathrm{CO}_{2}$ methanation. The promotion with $\mathrm{V}$ significantly changes textural properties (specific surface area and mesoporosity) and improves the dispersion of nickel. Moreover, the vanadium promotion strongly influences the surface basicity by increasing the total number of basic sites. An optimal loading of $2 \mathrm{wt} \%$ leads to the highest activity in $\mathrm{CO}_{2}$ methanation, which is directly correlated with specific surface area, as well as the basic properties of the studied catalysts.
\end{abstract}

Keywords: methanation; hydrotalcite; vanadium; nickel catalyst; mixed oxides; $\mathrm{CO}_{2}$ hydrogenation

\section{Introduction}

The emission of greenhouse gases, especially $\mathrm{CO}_{2}$, is an important problem that society is currently facing [1]. Considering the increasing threat related to global warming, such as the intensification of floods/drought periods, heat waves, and temperature rise [2,3], more restrictive politics related to $\mathrm{CO}_{2}$ emissions are being introduced. In December 2020, during the EU summit, it was decided to cut $55 \%$ of $\mathrm{CO}_{2}$ emissions before year 2030 [4]. Therefore, the fully decarbonized global industry is crucial to limit the climate change and to limit the global warming up to $2{ }^{\circ} \mathrm{C}$ by 2050-2070 [5]. This will involve an increase in energy efficiency for carbon capture, electrification, and sustainable production of hydrogen [5]. In this regard, carbon dioxide can be utilized in several chemical processes. Technologies such as the production of cyclic carbonates, dimethyl carbonate, and hydrogenation of $\mathrm{CO}_{2}$ to methanol have already been developed on an industrial scale [6]. In addition, the $\mathrm{CO}_{2}$ hydrogenation process to methane is an emerging technology and has been industrialized by companies such as Audi, DVGW, etc. [7].

The $\mathrm{CO}_{2}$ methanation or Sabatier's reaction is based on the exothermic reaction (1) between carbon dioxide and hydrogen.

$$
\mathrm{CO}_{2}+4 \mathrm{H}_{2}=\mathrm{CH}_{4}+2 \mathrm{H}_{2} \mathrm{O}, \Delta \mathrm{H}_{298 \mathrm{~K}}=-165 \mathrm{~kJ} / \mathrm{mol}
$$

The products of the reaction are methane and water vapor, making it a solution for both the utilization of $\mathrm{CO}_{2}$ and the storage of chemical energy in the form of synthetic gas.

$\mathrm{CO}_{2}$ methanation is a kinetically limited catalytic process, requiring the design of a stable and selective catalyst. A commercially available catalyst used for this process is alumina-supported nickel $\left(\mathrm{Ni} / \mathrm{Al}_{2} \mathrm{O}_{3}\right)$. Still, this material can be improved to ensure prolonged lifetime $[8,9]$. $\mathrm{Ni} / \mathrm{Al}_{2} \mathrm{O}_{3}$ catalysts are prone to sintering of nickel particles on the surface at high temperatures and the deactivation of active centers below $250{ }^{\circ} \mathrm{C}$ [10]. 
Additionally, the activity of the monometallic nickel catalyst is assigned to the concentration of nickel: the higher the content of nickel, the better the activity [11]. These problems can be overcome in several ways, for example, by substituting nickel for another type of active material such as rhodium or ruthenium. The latter metals are more stable and their low loadings is sufficient to provide satisfactory activity. On the other hand, the use of noble metals is expensive and requires special utilization, making the production of such catalysts uneconomical. The activity of the nickel-based catalyst can be improved by changing the synthesis method to one that provides better dispersion of the active phase and improved metal-support interaction, which may limit sintering to a certain extent [12].

An effective synthesis of multielemental catalysts, with dedicated metal-support interaction could be the thermal decomposition of hydrotalcites. Hydrotalcites are layered double hydroxides, with water and ions present in the interlayer region, with the chemical formula presented in Equation (2) [13]. Brucite-like layers in natural hydrotalcite are formed with $\mathrm{Mg}$ and $\mathrm{Al}$ ions, although during the synthesis of synthetic minerals it is possible to substitute them with other elements of similar atomic radius, which allows the preparation of complex, uniform materials [14]. Above $400{ }^{\circ} \mathrm{C}$, hydrotalcite undergoes thermal decomposition to mixed oxides with a periclase-like crystalline structure. Reduction of this type of oxides leads to the formation of nickel nano-crystallites resistant towards sintering due to the strong metal-support interaction and high dispersion [11].

$$
\begin{gathered}
{\left[\mathrm{M}_{(1-\mathrm{x})}^{2+} \mathrm{M}_{\mathrm{x}}^{3+}(\mathrm{OH})_{2}\right]^{\mathrm{x}+}\left(\mathrm{A}^{\mathrm{n}-{ }_{\mathrm{x}}}\right) \cdot \mathrm{mH}_{2} \mathrm{O}} \\
\mathrm{M}^{2+} \text { - bivalent metal ion, } \\
\mathrm{M}^{3+} \text { - trivalent metal ion, } \\
\mathrm{x} \text { from } 0.2 \text { to } 0.33 \\
\mathrm{~A} \text { - anion }
\end{gathered}
$$

Additionally, choosing a more complex support material may improve its interaction with the active phase and provide better acidic-basic properties [15]. $\gamma$-Alumina is inexpensive, provides satisfactory surface properties, and inhibits nickel sintering [16]. In addition, its basic properties can be improved via the addition of stronger centers, such as magnesium or cerium to increase the $\mathrm{CO}_{2}$ adsorption capacity [17].

Another promising solution is the promotion of supported nickel catalysts with other types of transition metals. This promotion can prevent the sintering of nickel, improve the dispersion, and can modify the surface properties leading to higher activity in $\mathrm{CO}_{2}$ methanation. The most commonly used promotors are copper [18], yttrium [19], or manganese [20]. Additionally, lathanum was found to work as a structural promoter, by limiting the number of side reactions [21,22]. Electronic promoters such as molybdenum [23], iron [20], or cobalt [24] are responsible for increasing the electron density of the catalytic sites, consequently increasing the catalytic activity. Vanadium was found to be a promising catalytic solution for catalytic $\mathrm{CO}_{2}$ utilizations [25-29]. For double-layered materials, vanadium can be introduced into the hydrotalcite structure both by interlayer doping or by layer doping. Interlayer doping occurs via incorporation of the vanadate complex to the the brucite-like layers, whereas layer doping is based on the introduction of $\mathrm{V}^{3+}$ ions to the brucite layers, partially replacing $\mathrm{Al}^{3+}[30,31]$.

When used as promotor, vanadium is recognized as a potential $\mathrm{CO}_{2}$ methanation catalyst. Thus vanadium was found to increase Ni dispersion, enhance $\mathrm{H}_{2}$ uptake, and additionally, $\mathrm{VOx}$ provides an electronic effect that can promote the dissociation of $\mathrm{CO}$ in the methanation reaction [26-29]. In our previous study, $\mathrm{Mg}-\mathrm{Al}-\mathrm{V}$ hydrotalcites with a vanadium loading from 0 to $4 \mathrm{wt} \%$ were impregnated with nickel and subsequently used as catalysts for $\mathrm{CO}_{2}$ methanation. The obtained results confirmed the promotion effect of vanadium throughout the increase of the Ni dispersion, the increase of specific surface area, and an optimal content of weak and medium strength basic sites [32].

In the present study, the preparation method was modified to a one-step synthesis. The active phase was synthesized simultaneously with the support during the co-precipitation 
at constant $\mathrm{pH}$. This synthesis approach may allow better availability of vanadium on the catalyst surface and thus lead to high catalytic activity.

\section{Results}

\subsection{Catalytic Tests}

\subsubsection{Temperature Programmed Surface Reaction}

Samples were tested in the $\mathrm{CO}_{2}$ methanation reaction as a function of temperature. Results are presented in Figure 1a. Among the tested materials, the highest catalytic activity was demonstrated by a sample containing $2 \mathrm{wt} \%$ vanadium. The Ni-CP-V2.0 catalyst not only reached satisfactory activity at temperatures higher than $350^{\circ} \mathrm{C}$, but was also significantly active at $250{ }^{\circ} \mathrm{C}$ compared to other materials. The samples containing 0,1 , and $4 \mathrm{wt} \%$ of vanadium showed no significant activity below $350^{\circ} \mathrm{C}$. Among them, the most active was the unpromoted catalyst (Ni-CP-V0.0). Ni-CP-V1.0 resulted in slightly better catalytic performance than Ni-CP-V4.0, which may suggest that the increase of vanadium loading is not favorable. This statement can be confirmed by the selectivity of the tested catalysts at the temperature of $300{ }^{\circ} \mathrm{C}$ (Figure 1b). The only sample that resulted in the near-equilibrium (99-98\%) selectivity to methane was the $2 \mathrm{wt} \% \mathrm{~V}$ promoted sample. The unpromoted catalyst operated with a high selectivity of ca. $95 \%$ during the entire test.

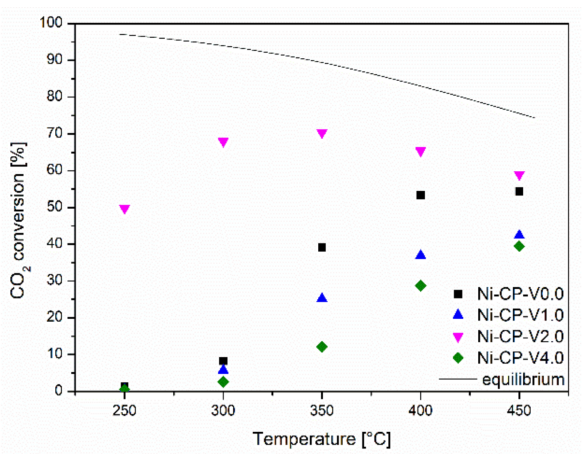

(a)

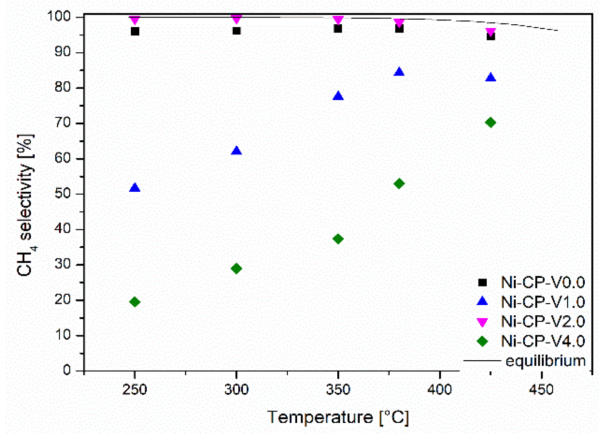

(b)

Figure 1. (a) $\mathrm{CO}_{2}$ conversion as a function of temperature; (b) $\mathrm{CH}_{4}$ selectivity as a function of temperature for hydrotalcite-derived catalysts.

For the catalysts containing 1 and $4 \mathrm{wt} \%$ vanadium, the selectivity at low temperatures was rather related to the formation of carbon monoxide. Ni-CP-V4.0 was more selective towards $\mathrm{CO}$ than Ni-CP-V1.0, although both of them mainly promoted the reverse watergas shift reaction (RWGS). This is in good agreement with the study of Le et al., which confirmed that the main product of the reaction is carbon monoxide, formed mainly in the RWGS reaction [33]. A similar effect was observed for other types of promoters such as copper, especially promoted on hydrotalcite-derived catalysts [18].

\subsubsection{Stability Tests at $300{ }^{\circ} \mathrm{C}$}

Steady-state tests were carried out at $300{ }^{\circ} \mathrm{C}$ for $5 \mathrm{~h}$ for all studied catalyst at the same operating conditions and presented in Figure 2. A similar trend in activity at $300{ }^{\circ} \mathrm{C}$ was observed when compared to that recorded during the TPSR test. The conversions for Ni-CP-V0.0, Ni-CP-V1.0, Ni-CP-V2.0, and Ni-CP-V4.0 were slightly higher (ca. 10\%) and stable during the entire $5 \mathrm{~h}$ test. The $\mathrm{CH}_{4}$ selectivity was found to be stable and higher than 91\% for both Ni-CP-V0.0 and Ni-CP-V1.0. However, the methane selectivity for Ni-CP-V4.0 decreased from 84 to $79 \%$, showing a possible negative impact of high $\mathrm{V}$ loading, which is favorable for $\mathrm{CO}$ production [33]. Finally, Ni-CP-V2.0 showed high conversion and high methane selectivity during time on stream. 


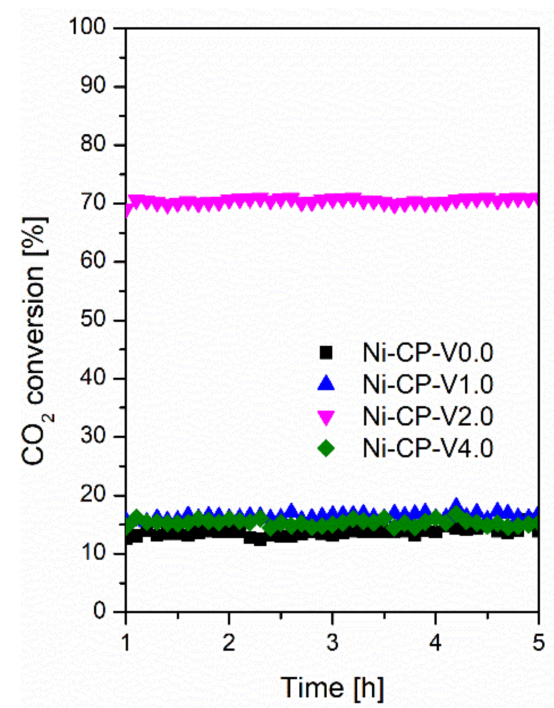

(a)

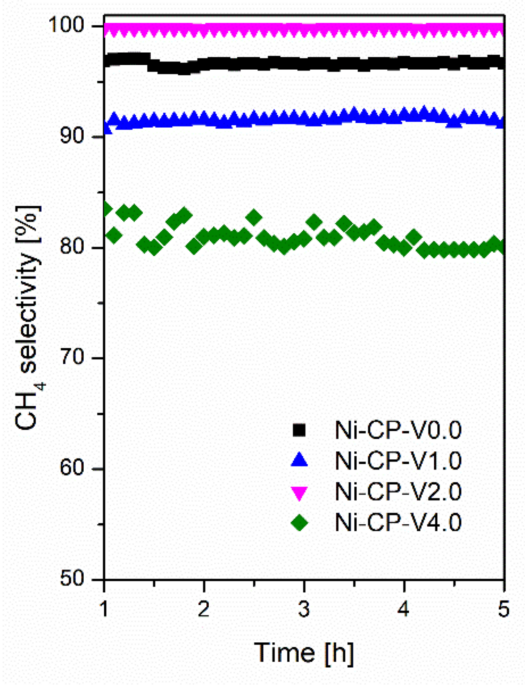

(b)

Figure 2. (a) $\mathrm{CO}_{2}$ conversion as a function of time at $300{ }^{\circ} \mathrm{C}$; (b) $\mathrm{CH}_{4}$ selectivity as a function of time at $300{ }^{\circ} \mathrm{C}$ for hydrotalcite-based catalysts.

Additionally, the dispersion (D) and the turnover frequency (TOF) were calculated to measure the efficiency of studied catalysts (the procedure presented in SI). Calculations are based on the performance registered during the stability test at $300{ }^{\circ} \mathrm{C}$. Among the studied catalysts, Ni-CP-V2.0 turned out to be the most efficient material with the highest value of TOF $\left(7.9 \times 10^{-2} \mathrm{~s}^{-1}\right)$ (Table 1$)$. The catalysts containing 1 and $4 \mathrm{wt} \%$ vanadium resulted in the same dispersion value, and TOF of 3.5 and $3.1 \times 10^{-2} \mathrm{~s}^{-1}$, respectively. $\mathrm{Ni}-\mathrm{CP}-\mathrm{V} 0.0$ presented the lowest turnover frequency, but higher dispersion. On the other hand, Ni-CP-V2.0 showed considerably higher TOF values compared to other promoted hydrotalcite-derived catalysts reported in the literature. Summa et al. studied promotion of $\mathrm{Cu}$ under the same conditions of $\mathrm{CO}_{2}$ methanation $\left(300{ }^{\circ} \mathrm{C}\right.$ and GHSV of $\left.12,000 \mathrm{~h}^{-1}\right)$. In this study the best performing Cu-promoted catalyst $(20 \mathrm{wt} \% \mathrm{Ni}$ and $1 \mathrm{wt} \% \mathrm{Cu}$ ) revealed TOF of $5.91 \times 10^{-2} \mathrm{~s}^{-1}$ [18]. Another example can be La-promoted hydrotalcite-based catalyst containing $40 \mathrm{wt} \%$ of nickel and $2 \mathrm{wt} \%$ of lanthanum. In the study of Wierzbicki et al., TOF was found to be equal $3.4 \times 10^{-2} \mathrm{~s}^{-1}\left(250^{\circ} \mathrm{C}\right.$ and GHSV of $\left.12,000 \mathrm{~h}^{-1}\right)$ [22].

Table 1. Turnover frequency and dispersion for hydrotalcite-derived catalysts.

\begin{tabular}{ccccc}
\hline Sample & Ni-CP-V0.0 & Ni-CP-V1.0 & Ni-CP-V2.0 & Ni-CP-V4.0 \\
\hline TOF $\left[10^{-2} \mathrm{~s}^{-1}\right]$ & 1.2 & 3.5 & 7.9 & 3.1 \\
$D$ & 0.08 & 0.04 & 0.07 & 0.04 \\
\hline
\end{tabular}

In order to understand these trends, the following sections present the physicochemical characterizations of the tested catalysts.

\subsection{Physico-Chemical Properties of V-Promoted Catalysts \\ 2.2.1. Catalyst Reducibility}

$\mathrm{H}_{2}$-TPR measurements were performed in order to investigate the reducibility of the studied hydrotalcite-derived samples. For all tested samples, a broad peak was observed at the high temperature region $\left(740-850^{\circ} \mathrm{C}\right)$ (Figure 3). 


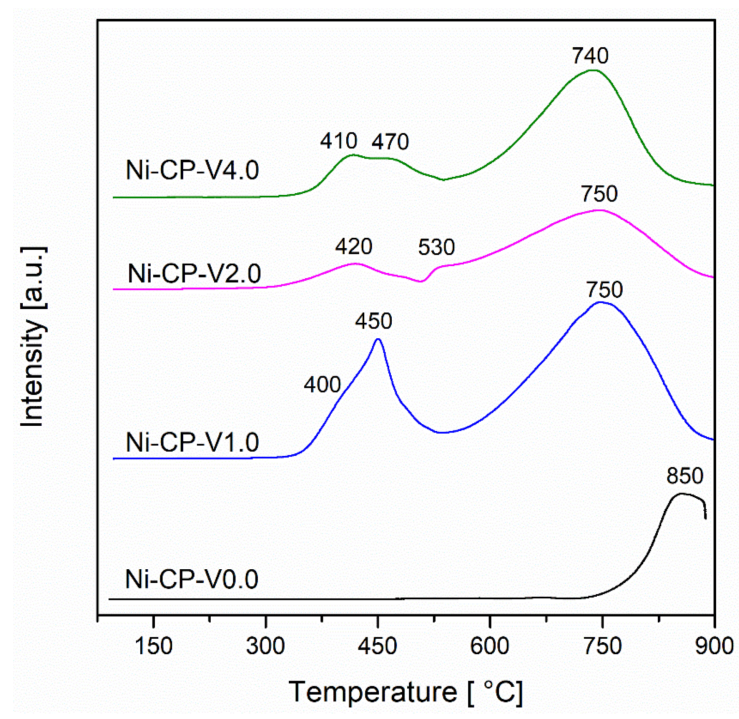

Figure 3. $\mathrm{H}_{2}$-TPR profiles for calcined hydrotalcites.

This peak can be assigned to the reduction of the nickel present in the periclase-like mixed-oxide structure. This typical reaction temperature peak at ca. $850^{\circ} \mathrm{C}$ corresponds to the reduction of ca. $20 \mathrm{wt} \%$ of nickel in the $\mathrm{Ni} / \mathrm{Mg} / \mathrm{Al}$ matrix [11,34]. This later peak is shifted to lower temperatures, with the increase of vanadium content, with a maximum at $740{ }^{\circ} \mathrm{C}$ for Ni-CP-V4.0. This shift can be explained by the weakening of the interaction between nickel and the oxide matrix, under the influence of vanadium. In our previous study, the reduction of impregnated $\mathrm{V}$ from $\mathrm{Mg}$-Al hydrotalcite-derived oxide matrix was investigated (Figure S1). The collected profiles showed a narrow peak at $590-610^{\circ} \mathrm{C}$, corresponding to the reduction of vanadium from $\mathrm{V}^{5+}$ to $\mathrm{V}^{4+}$ [35]. Since $\mathrm{V}^{5+}$ is reduced in the temperature range of the measurement, it is possible to assume that it ungergoes simulateous reduction with nickel [36].

For V-promoted catalysts, additional low-temperature peaks with two maximums are detected. A broad and intense peak was observed for the Ni-CP-V1.0 sample with a shoulder at $400{ }^{\circ} \mathrm{C}$, and a sharp peak with maximum at $450{ }^{\circ} \mathrm{C}$. According to the literature, these peaks correspond to the reduction of weakly bonded nickel oxides. The intensity of these peaks obtained at low-temperature region decreases with the loading of vanadium. Additionally, the reduction temperature of these peaks increased slightly, ca. $10-20^{\circ} \mathrm{C}$, suggesting stronger interaction of surface $\mathrm{NiO}$ with the support.

\subsubsection{Low-Temperature $\mathrm{N}_{2}$ Sorption on Studied Catalysts}

Low-temperature $\mathrm{N}_{2}$ sorption measurements were performed to investigate the structure properties of the examined samples. All materials resulted in an isotherm with a well-defined hysteresis loop typical for the type IV of isotherm, classified additionally as a subtype H1, typical for mesoporous materials (Figure S2). H1 subtype suggests the presence of cylindrical-like pore channels or agglomerates of approximately uniform spheres [37]. Hydrotalcite-derived mixed oxides usually present such a type of surface structure, which is compared in Table 2 [18]. The specific surface area is 179 and $207 \mathrm{~m}^{2} / \mathrm{g}$ for the samples with 1 and $4 \mathrm{wt} \%$ of vanadium, respectively. Additionally, the mesopore volume of those materials was ca. $20 \mathrm{~cm}^{3} / \mathrm{g}$. The highest $S_{\mathrm{BET}}$ of $306 \mathrm{~m}^{2} / \mathrm{g}$ was obtained with the Ni-CP-V2.0 catalyst. This catalyst additionally resulted in the highest volume of mesopores $\left(0.70 \mathrm{~cm}^{3} / \mathrm{g}\right)$. The difference in the surface properties is significant and can be assigned as one of the most important factors related to the catalytic activity, since a well-developed surface allows for a better dispersion of active sites. 
Table 2. Specific surface area, mean pore diameter, and volume of mesopores of the calcined catalysts.

\begin{tabular}{ccccc}
\hline Sample & $\mathbf{S}_{\text {BET }}\left[\mathbf{m}^{\mathbf{2}} / \mathbf{g}\right]$ & Mean Pore Diameter $[\mathbf{n m}]$ & Mesopore Volume $\left[\mathrm{cm}^{\mathbf{3}} / \mathbf{g}\right]$ & Isotherm Type \\
\hline Ni-CP-V0.0 & 241 & 10 & 0.42 & IV-H1 \\
Ni-CP-V1.0 & 179 & 10 & 0.18 & IV-H1 \\
Ni-CP-V2.0 & 306 & 11 & 0.70 & IV-H1 \\
Ni-CP-V4.0 & 207 & 10 & 0.22 & IV-H1 \\
\hline
\end{tabular}

The unpromoted sample presented a specific surface of $241 \mathrm{~m}^{2} / \mathrm{g}$, with a mesopore volume of $0.42 \mathrm{~cm}^{3} / \mathrm{g}$. Mean pore diameter for all hydrotalcite-derived oxides was similar with ca. $10 \mathrm{~nm}$. It is generally assumed that an increase of the promoter loading in hydrotalcite-based catalyst can lead to a decrease of the specific surface area due to the blockage of mesopores [38,39].

\subsubsection{Evolution the Crystalline Structure of the Catalysts}

To investigate the evolution of the crystalline composition of V-promoted hydrotalcites, XRD was performed on both calcined and reduced samples (Figure $4 a, b$ ). The thermal decomposition of hydrotalcite is temperature sensitive. Above $300{ }^{\circ} \mathrm{C}$, the structure of $\mathrm{Mg}-\mathrm{Al}$ hydrotalciteis is replaced with an oxide similar to periclase [40]. The crystallinity of the resulting phase increases with increasing temperature of calcination. It has been reported that additionally above $600-700{ }^{\circ} \mathrm{C}$, spinel-type oxide may form in thermally decomposed hydrotalcites $[40,41]$. During calcination, the structure of hydrotalcite was broken down into mixed oxides similar to periclase. All tested samples showed five intense reflexions at $2 \theta$ of 37.32 (111), 43.36 (020), 62.99 (022), 75.56 (131), and 79.57 (222), confirming the expected periclase (ICDD 01-087-0653). The scattering characteristic of the amorphous phase was not detected, the peaks were uniform and broad, suggesting a small crystallite size and a decrease in crystallinity. Among the V-promoted samples, a residual phase of hydrotalcite was detected in all materials, suggesting no complete thermal decomposition of the parent structure. It may suggest that the presence of vanadium leads to an increase in the temperature of thermal decomposition of hydrotalcite, most likely throughout increasing the strength of coordination binding in brucite-like layers, requiring more energy to remove -OH groups.

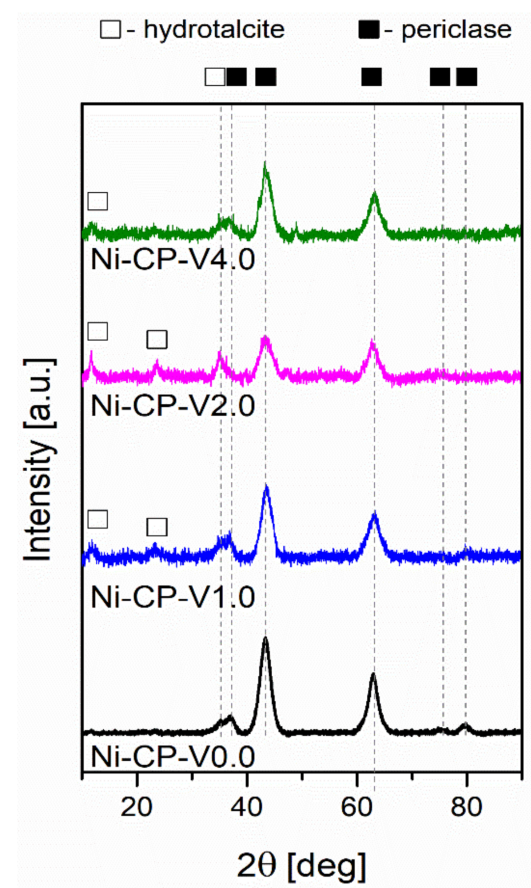

(a)

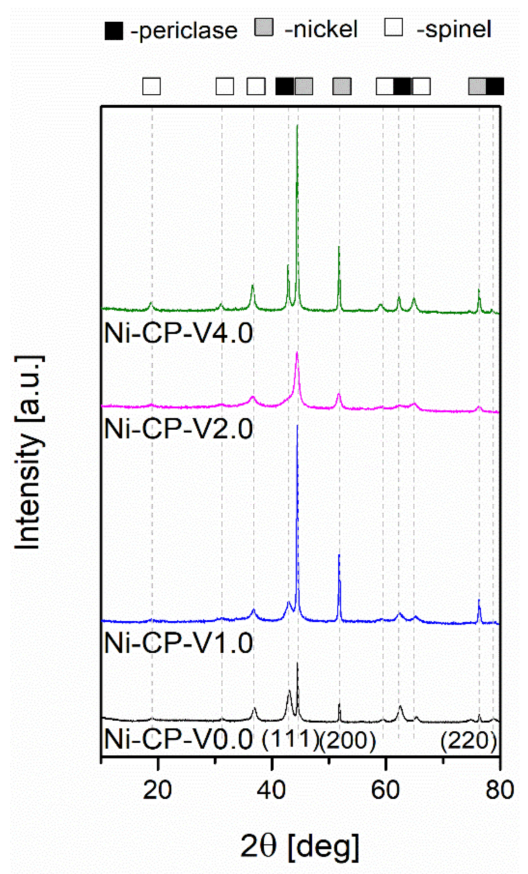

(b)

Figure 4. XRD diffractograms for (a) catalysts after calcination; (b) catalysts after reduction. 
On reduced catalysts, three phases were distinguished from X-ray diffractograms, such as periclase (ICDD 00-045-0946) already discussed in Figure 4a, spinel (ICDD 01-070-5187), and metallic nickel (ICDD 03-065-0380). The source of the emerging nickel phase was the reduction of nickel species present in the periclase-like structure and a such crystalline phase was confirmed with three sharp and narrow reflections at $2 \theta$ of 44.3 (111), 51.7 (200), 76.1 (220), typical for metallic nickel. Spinel-type oxide is usually formed at high-temperatures, below $900{ }^{\circ} \mathrm{C}$, at which the reduction was carried out, the temperature was sufficiently high to form such structure. This phase was most likely formed from periclase-like oxide and the obtained spinel oxide was $\mathrm{MgAl}_{2} \mathrm{O}_{4}$, as confirmed by the reflections at $2 \theta$ of $19.0 \mathrm{deg}$ (111), $31.3 \mathrm{deg}$ (220), $36.8 \mathrm{deg}$ (311), $44.8 \mathrm{deg}$ (400), $59.3 \mathrm{deg}$ (511), and $65.2 \mathrm{deg}$ (440). Additionally, a certain difference in the intensity in the diffractograms of the samples was visible: Ni-CP-V0.0 and Ni-CP-V2.0 resulted in much lower intensity of the nickel-related reflections, suggesting a small nize of the nickel crystallites in the sample. For Ni-CP-V1.0 and Ni-CP-V4.0, the reflections assigned to nickel are very intense, narrow, and sharp, indicating a relatively large size of metal crystallites. After the reduction step, no additional peaks related to vanadium oxide or other vanadium species were detected. Additionally, there is no shift in the position of the reflexions characteristic to nickel, suggesting that the $\mathrm{Ni}-\mathrm{V}$ solid solution is not formed.

Based on Rietveld refinements, the fraction of each of the detected crystalline phases was calculated, based on the height, width, and position of the reflexions. Results are compared in Table 3. Several trends were possible to distinguish. The content of spinel was increased with the amount of vanadium promotion, from 28.6 for Ni-CP-V0.0 up to $50.1 \%$ for Ni-CP-V4.0. On the contrary, with the increase of vanadium content, the share of periclase-like oxide structure was decreased from $63.1 \%$ for the unpromoted catalyst to $23.5 \%$ for the sample with the highest loading of vanadium. The content of metallic nickel phase was of 18-19\% for Ni-CP-V0.0 and V2.0, while V1.0 and V4.0 catalysts resulted in ca. $26 \%$. Additionally, crystallite size based on the Scherrer's equation was calculated for nickel. The smallest crystallites were found in the Ni-CP-V2.0 catalyst-with a size of ca. $6 \mathrm{~nm}$. Larger crystallites were found for the unpromoted sample, of ca. $15 \mathrm{~nm}$. Nickel particles of 31 and $33 \mathrm{~nm}$ were found for Ni-CP-V4.0 and Ni-CP-V1.0 samples. The samples with the larger nickel particle size were those with a higher content of nickel detected on the surface. It may suggest that during the reduction step formation of bigger crystallites was favoured due to the higher amount of nickel available on the surface.

Table 3. Results of Rieteveld refinements and $\mathrm{Ni}^{0}$ crystallite size calculated based on Scherrer's equation, for reduced hydrotalcite-derived samples.

\begin{tabular}{cccccc}
\hline Sample & \multicolumn{2}{c}{ Share of Crystalline Phase } & \multicolumn{2}{c}{ Ni $^{\mathbf{0}}$ Crystallite Size [nm] } \\
\hline & Spinel [\%] & Periclase [\%] & Nickel [\%] & XRD & TEM \\
\hline Ni-CP-V0.0 & 28.6 & 52.9 & 18.5 & 15 & 12 \\
Ni-CP-V1.0 & 36.2 & 36.8 & 26.9 & 33 & 28 \\
Ni-CP-V2.0 & 42 & 38.9 & 19.1 & 6 & 15 \\
Ni-CP-V4.0 & 50.1 & 23.5 & 26.3 & 31 & 28 \\
\hline
\end{tabular}

\subsubsection{Surface Basicity of the Reduced Catalysts}

$\mathrm{CO}_{2}$-TPD was performed to evaluate the number of basic sites available on the surface of the reduced hydrotalcite-derived catalysts. $\mathrm{CO}_{2}$-TPD profiles (Figure 5) were deconvoluted into three gaussian curves with maxima at the ranges $125-150{ }^{\circ} \mathrm{C}, 185-220^{\circ} \mathrm{C}$, and 270-340 ${ }^{\circ} \mathrm{C}$, corresponding to weak, medium-strenght, and strong basic sites, subsequently. The values corresponding to distribution of each type of sites are compared in Table 2 . The lower number of total basic sites was found for the non-promoted catalyst Ni-CP-V0.0. With the increase of vanadium content, the amount of basic sites significantly increases. Promotion with $1 \mathrm{wt} \%$ of $\mathrm{V}$ resulted in doubling the number of total basic sites, confirming the strong basic properties of vanadium. 


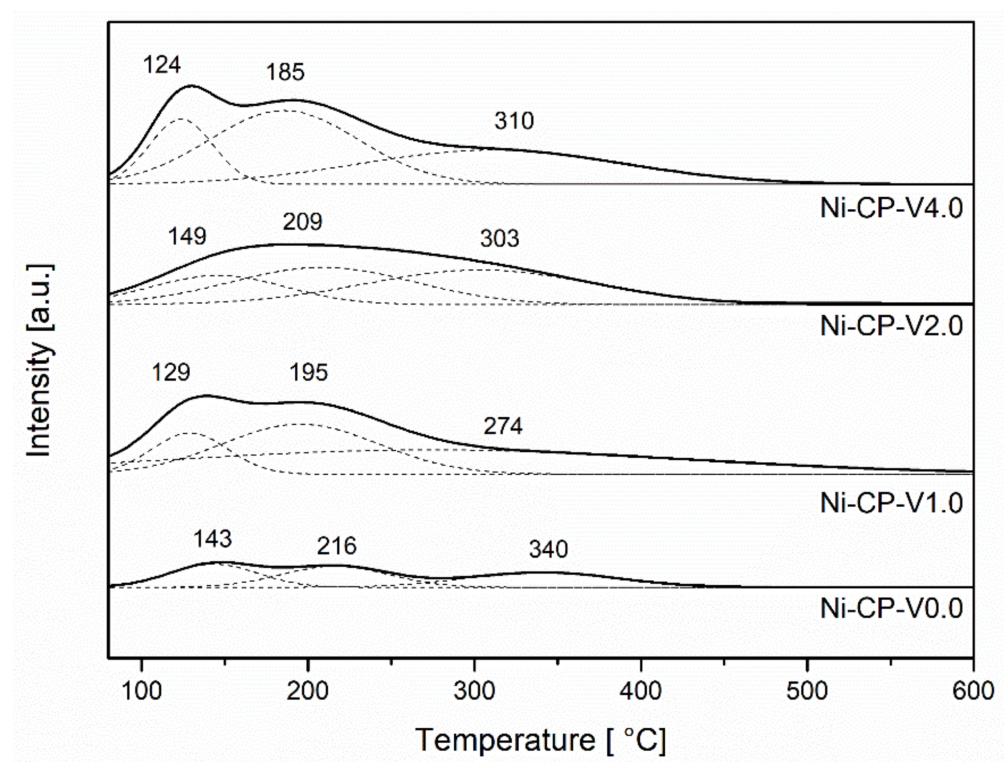

Figure 5. $\mathrm{CO}_{2}$-TPD profiles for reduced hydrotalcites.

In the studied V-promoted catalysts, medium strength basic sites, which have been reported to play an important role in the $\mathrm{CO}_{2}$ methanation reaction [22], were the most abundant. For the unpromoted hydrotalcite-derived catalyst, the distribution of the types of basic sites is uniform, and no type of sites were found to be dominating. Additionally, with the increase of vanadium promotion, the number of strong basic sites assigned to Lewis basic sites associated with oxygen anions increased [42]. The main role assigned to the basic sites is improvement of the chemisorption of $\mathrm{CO}_{2}$ on the support and prevention of cokeformation on the catalyst surface [43].

During methanation reaction, $\mathrm{CO}_{2}$ forms monodentate carbonates on basic lowcoordination oxygen anions that are present at the surface, especially in $\mathrm{MgO}$ [18]. The temperature of $\mathrm{CO}_{2}$ desorption from the strong sites is decreased for $\mathrm{V}$-containing materials, which suggests a weakened interaction of unidenate ions in comparison to the unpromoted material, or lower availability of $\mathrm{MgO}$ on the surface. Ni-CP-V2.0 is the sample with the highest number of weak basic sites assigned to Brønsted basic centers, such as hydroxyl groups where bicarbonate is formed (Table 4). Ni-CP-V4.0 was found to be dominating in the case of medium strength basic sites characterized as Lewis acid base sites, where $\mathrm{CO}_{2}$ forms bidentate carbonates on metal-oxygen pairs. For Ni-CP-V0.0 and Ni-CP-V2.0 low and moderate temperature peaks were shifted ca. $20^{\circ} \mathrm{C}$ to higher temperatures, suggesting stronger interactions between $\mathrm{CO}_{2}$ and sites in those two samples.

Table 4. Basicity (from $\mathrm{CO}_{2}-\mathrm{TPD}$ ) of reduced samples.

\begin{tabular}{cccccccc}
\hline \multirow{2}{*}{ Sample } & \multicolumn{3}{c}{ Basic Sites $[\mu \mathrm{mol} / \mathrm{g}]$} & \multicolumn{3}{c}{ Basic Sites Distribution [\%] } \\
\cline { 2 - 7 } & Weak & Medium & Strong & Total & Weak & Medium & Strong \\
\hline $\begin{array}{c}\text { Ni-CP- } \\
\text { V0.0 }\end{array}$ & 23 & 25 & 25 & 73 & 32 & 34 & 34 \\
$\begin{array}{c}\text { Ni-CP- } \\
\text { V1.0 }\end{array}$ & 36 & 86 & 37 & 159 & 23 & 54 & 23 \\
$\begin{array}{c}\text { Ni-CP- } \\
\text { V2.0 }\end{array}$ & 51 & 71 & 55 & 177 & 29 & 40 & 31 \\
$\begin{array}{c}\text { Ni-CP- } \\
\text { V4.0 }\end{array}$ & 37 & 98 & 59 & 194 & 19 & 51 & 30 \\
\hline
\end{tabular}

2.2.5. Morphology and Structure of Catalysts by Transmission Electron Microscopy

Figure 6 shows HRTEM images for Ni-CP-V0.0, (Figure 6(1A,1B)), Ni-CP-V1.0 (Figure 6(2A,2B), Ni-CP-V2.0 (Figure 6(3A,3B), and Ni-CP-V4.0 (Figure 6(4A,4B), with 
histograms (bin width calculated by the rice-estimator [44]) representing the distribution of nickel particle sizes. From Figure 6, one can conclude that the distribution of the nickel particles is uniform in all the hydrotalcite-derived samples.
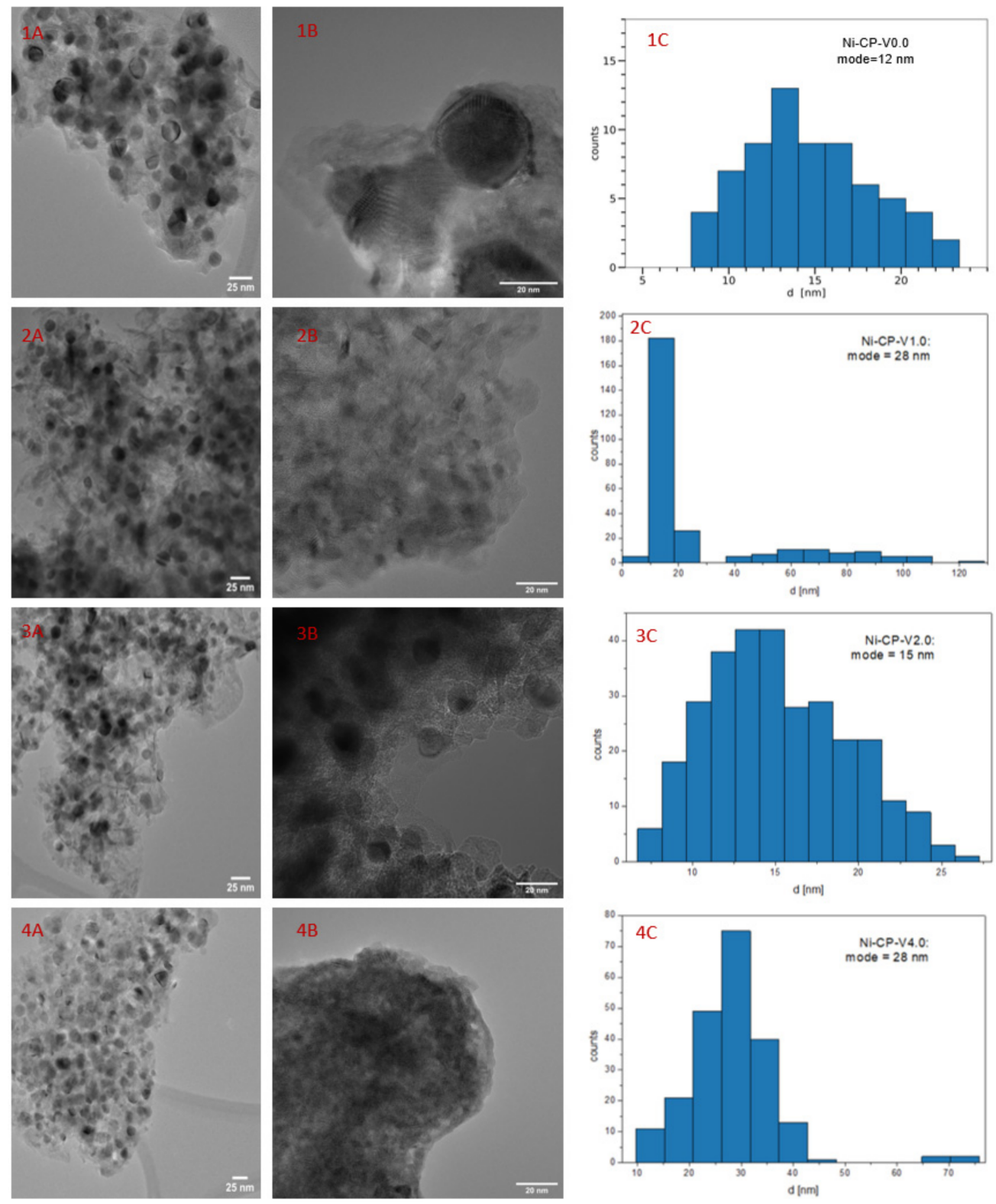

Figure 6. 1-4 (A,B) TEM images for the reduced hydrotalcite-derived samples; 1-4 (C) histograms for $\mathrm{Ni}^{0}$ particle diameter.

$\mathrm{The} \mathrm{Ni}^{0}$ average particle size were found as follow: 12, 11, 15, and 28 for Ni-CP-V0.0, $\mathrm{Ni}-\mathrm{CP}-\mathrm{V} 1.0, \mathrm{Ni}-\mathrm{CP}-\mathrm{V} 2.0$, and Ni-CP-V4.0, respectively (Figure 6(C)). Furthermore, the results obtained by TEM suggest that the size of nickel crystallites increased with the increase of vanadium loading, which is not in line with the XRD results. On the contrary, in the literature, on V-Mg-Al mixed oxides impregnated with nickel, it was found that optimal vanadium loading ( $2 \mathrm{wt} \%$ ) led to lower $\mathrm{Ni}^{0}$ particle size [32].

Additionally, energy dispersive X-ray (EDX) mapping analysis were performed on V-promoted samples (Ni-CP-V2.0 and Ni-CP-V4.0), to investigate the distribution of $\mathrm{Ni}$ and V on the sample (full EDX analyses are presented in Figures S3 and S4 in the Supplementary Materials). Nickel particles appeared to be regularly shaped spherical crystallites. Vanadium was found to be homogenously dispersed in the support and no enrichment was found at the positions of the Ni particles. This seems to exclude the formation of solid 
$\mathrm{V} / \mathrm{Ni}$ solutions with a significant vanadium content even when the $\mathrm{V}$ loadings increased as reported elsewhere [45].

\subsection{Post-Run Characterizations}

XRD was carried out on post-run samples to investigate the possible changes in the crystalline structure of the tested hydrotalcite-derived catalysts and a possible sintering of Ni particles. For all samples, three types of a crystalline phase were detected. Those phases were: periclase (ICDD 01-087-0653), spinel (ICDD 01-070-5187), and metallic nickel (ICDD 03-065-0380), similarly to the reduced materials. Additionally, in the non-promoted catalyst, $\mathrm{Ni}-\mathrm{CP}-\mathrm{V} 0.0$, residual hydrotalcite phase was registered. No scattering characteristic for amorphous phases was detected in the diffractograms, suggesting either lack of amorphous phases or presence in the amounts below the possibility of detection with this method.

The intensity of reflexions from periclase and spinel-like oxides is lower compared to the intensity of the $\mathrm{Ni}^{0}$ phase. This observation has already been described in the literature as the lack of stabilization of $\mathrm{NiO}$ particles on the surface. This phenomenon is observed when the nickel particles are not stabilized in the $\mathrm{Mg}$-Al oxide matrix and tend to migrate to the surface to sinter [46].

The nickel crystallites size was calculated based on Scherrer's equation (Figure 7). It was observed, that the large crystallites observed in reduced samples Ni-CP-V1.0 and $\mathrm{Ni}-\mathrm{CP}-\mathrm{V} 4.0$ before the methanation tests were redispersed to smaller ones, with a decrease in the average diameter of ca. 16 and $15 \mathrm{~nm}$. Moreover, the size of nickel crystallites on $\mathrm{Ni}$ $\mathrm{CP}-\mathrm{V} 2.0$ decreased, from 6 to $4 \mathrm{~nm}$. For unpromoted catalyst, after the catalytic test, a slight increase of the $\mathrm{Ni}^{\circ}$ particle was observed (from 15 to $17 \mathrm{~nm}$ ), suggesting a slight sintering. Since a decrease in nickel crystallite size was observed for all the V-promoted catalysts, it is possible to conclude that presence of vanadium modifies the surface properties, which leads to a redispersion of $\mathrm{Ni}^{\circ}$ on the catalyst. Similar behaviour was already observed for $\mathrm{Cu}-\mathrm{Ni}$ mixed oxides derived from hydrotalcites, in which a $\mathrm{Cu}-\mathrm{Ni}$ alloy could be formed. Such a redispersion was explained due to the susceptibility of nickel atoms to segregate from the solid solution more easily than copper [18,47]. Thus, It is possible to expect a similar effect either on vanadium promoted catalysts, although, EDX mapping confirmed lack of formation of $\mathrm{Ni}-\mathrm{V}$ alloy on the surface, so this behaviour could be assigned to the oxygen storage capacity of the $\mathrm{V}$ promoted catalyst, which can be intensified in this case by the electronic properties of $\mathrm{V}$ [48].

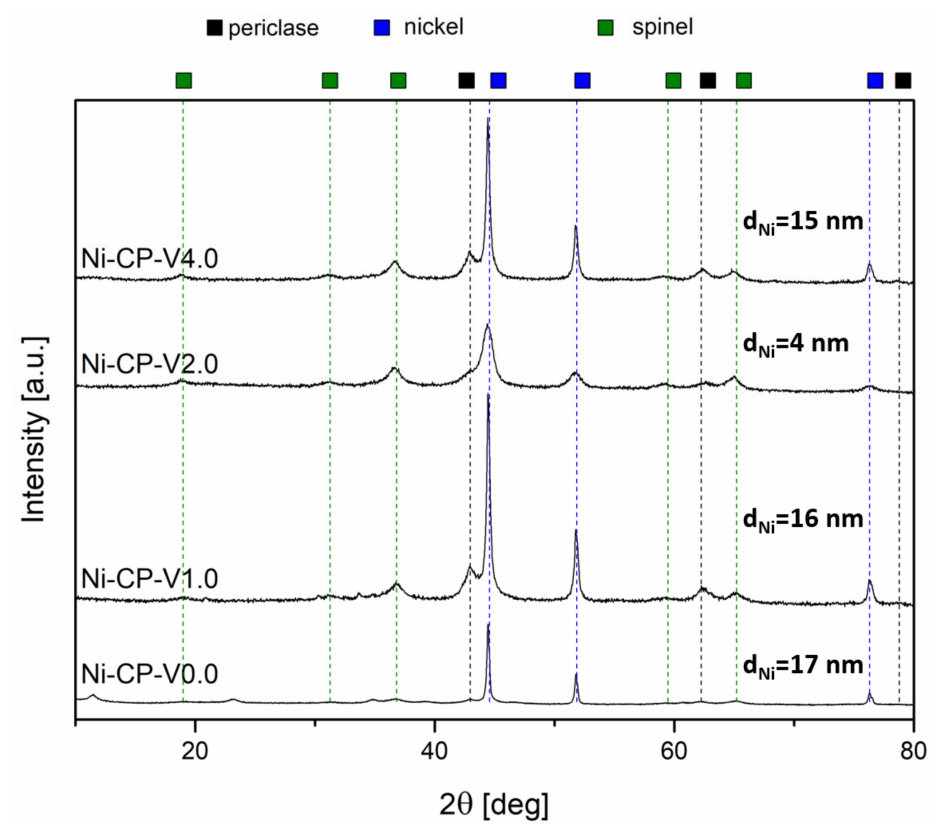

Figure 7. XRD diffractograms for spent hydrotalcite-derived catalyst. 
TEM image of spent Ni-CP-V2.0 catalyst (Figure 8) revealed small nickel crystallites, with an average diameter of ca. $10 \mathrm{~nm}$, whereas $15 \mathrm{~nm}$ were found on the reduced sample. This decrease confirms the tendency found previously in XRD. Thus, in our study it is possible to exclude the sintering of nickel. These later results confirmed the redistribution of nickel particle after methanation reaction. Moreover, one can note that the distribution of nickel in post-run sample was regular and similar to what was visible on the reduced catalysts before the test. Based on EDX mapping, no agglomeration of vanadium particles was detected-it seems that they remained in the Mg-Al oxide matrix, forming a homogenous solid solution (full EDX analyses are presented in Figures S5 and S6 in the Supplementary Materials).
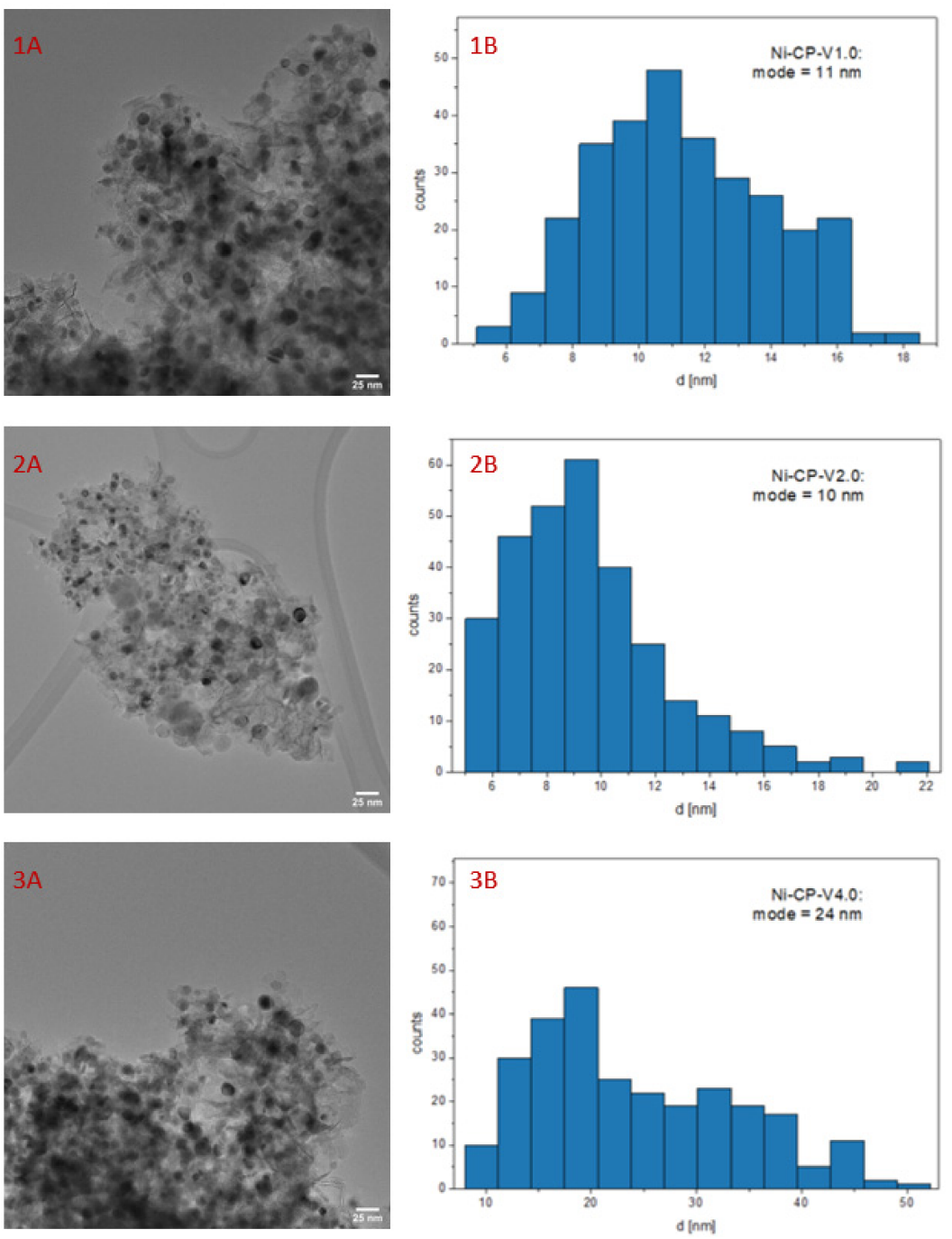

Figure 8. 1-3 (A) TEM image of spent V-promoted catalysts; 1-3 (B) histogram for spent Ni-CP-V2.0.

\section{Correlation between the Catalytic Activity and the Physico-Chemical Properties of} the Ni-CP-VX Catalysts

Based on the results of the $\mathrm{CO}_{2}$ methanation tests, and physico-chemical characterisation, it is possible to draw a correlation between the catalytic activity and the properties of the V-promoted nickel catalyst (Figure 9). The activity of $\mathrm{CO}_{2}$ conversion at $350{ }^{\circ} \mathrm{C}$ was correlated with $\mathrm{Ni}^{0}$ crystallite size, total number of basic sites, and specific surface area determined on the samples. A direct correlation was found between the $\mathrm{CO}_{2}$ conversion, specific surface area and $\mathrm{Ni}^{0}$ crystallite size. Among the studied materials, $\mathrm{Ni}-\mathrm{CP}-\mathrm{V} 2.0$ (72\% at $350{ }^{\circ} \mathrm{C}$ ) was found to be the best catalyst. This one possesses the higher specific surface area of $306 \mathrm{~m}^{2} / \mathrm{g}$ and the smaller nickel particles $(6 \mathrm{~nm})$. The ranking in terms of catalytic 
versus SSA and $\mathrm{Ni}^{\circ}$ particle size is then as follows: Ni-CP-V0.0. with a $\mathrm{CO}_{2}$ conversion of $40 \%$ at $350{ }^{\circ} \mathrm{C}$, a SSA of $241 \mathrm{~m}^{2} / \mathrm{g}$, and $\mathrm{Ni}^{0}$ particle size of ca. $15 \mathrm{~nm}>\mathrm{Ni}-\mathrm{CP}-\mathrm{V} 1.0\left(\mathrm{CO}_{2}\right.$ conversion $\left.=25 \%, \mathrm{~S}_{\mathrm{BET}}=179 \mathrm{~m}^{2} / \mathrm{g}, \mathrm{d}_{\mathrm{Ni}}{ }^{\circ}=33 \mathrm{~nm}\right)>\mathrm{Ni}-\mathrm{CP}-\mathrm{V} 4.0\left(\mathrm{CO}_{2}\right.$ conversion $=15 \%$, $\mathrm{S}_{\mathrm{BET}}=207 \mathrm{~m}^{2} / \mathrm{g}, \mathrm{d}_{\mathrm{Ni}}{ }^{\circ}=31 \mathrm{~nm}$ ). Thus as expected, parameters such as specific surface area and nickel particle size are correlated because an increase of the surface allows for a better dispersion of $\mathrm{Ni}^{0}$. As reported in the $\mathrm{CO}_{2} \mathrm{TPD}$ results, the promotion with vanadium led to one important increase of the surface basicity. Thus, the V-promoted materials resulted in a higher number of medium-strength and strong basic sites than on the unpromoted catalyst. Additionally, with the increase of vanadium content, the amount of total basic sites was increased as well. It was already reported in the literature that the increase of medium-strength basicity is related to an improvement of the catalytic activity [21]. It is worth to note that for the co-precipitated, $\mathrm{V}$-promoted $\mathrm{Ni}-\mathrm{Mg}$-Al hydrotalcite-derived catalysts, despite the significant improvement of the basic properties, especially in terms of medium-strength and strong basicity, there is no correlation between this property and $\mathrm{CO}_{2}$ conversion. Most likely, basicity was not the predominant factor here, in comparison to strongly varying specific surface area and dispersion.

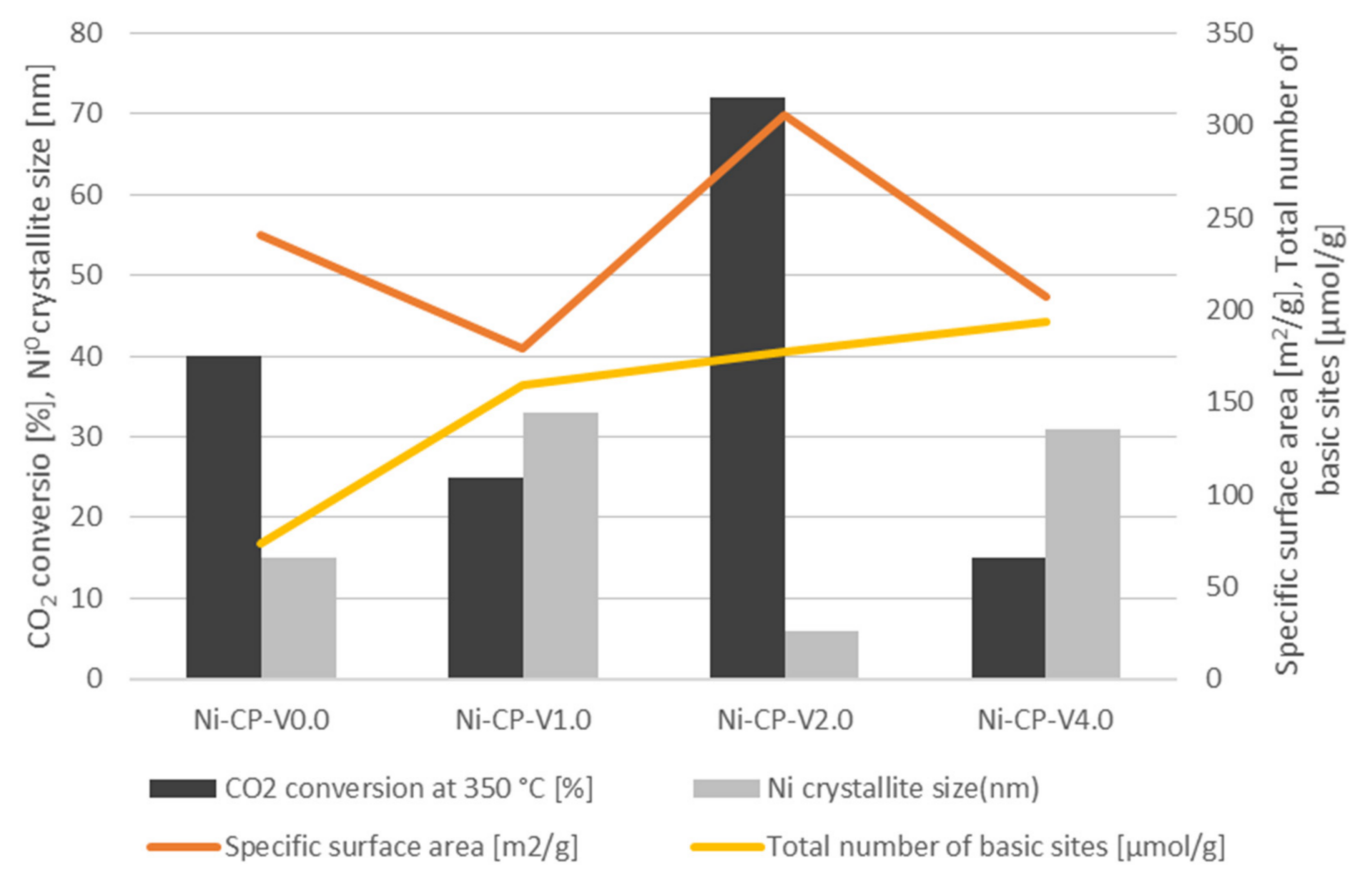

Figure 9. Corellation between vanadium content, $\mathrm{CO}_{2}$ conversion, $\mathrm{Ni}^{0}$ crystallite size for reduced samples (XRD), specific surface area $\left[\mathrm{m}^{2} / \mathrm{g}\right]$, and total number of basic sites $[\mu \mathrm{mol} / \mathrm{g}]$.

\section{Materials and Methods}

Samples were prepared via co-precipitation at constant $\mathrm{pH}$, as proposed by Cavani et al. [13]. $\mathrm{Mg}\left(\mathrm{NO}_{3}\right)_{2} \cdot 6 \mathrm{H}_{2} \mathrm{O}, \mathrm{Al}\left(\mathrm{NO}_{3}\right)_{3} \cdot 9 \mathrm{H}_{2} \mathrm{O}, \mathrm{Ni}\left(\mathrm{NO}_{3}\right)_{2} \cdot 6 \mathrm{H}_{2} \mathrm{O}$ and $\mathrm{VCl}_{3}$ were utilized for the synthesis. Samples were co-precipitated at a temperature of $65^{\circ} \mathrm{C}$, stabilizing the $\mathrm{pH}$ at the range $9.5-10$ by adding $1 \mathrm{M} \mathrm{NaOH}$ dropwise. The precipitate was aged in mother solution for $24 \mathrm{~h}$ at $65^{\circ} \mathrm{C}$, later washed with distilled water and dried overnight in static air at $80{ }^{\circ} \mathrm{C}$. Dry hydrotalcites were calcined for $5 \mathrm{~h}$ at $500{ }^{\circ} \mathrm{C}$ and reduced prior to the menthanation tests for $1 \mathrm{~h}$ at $900{ }^{\circ} \mathrm{C}$ in the $5 \% \mathrm{H}_{2} / \mathrm{Ar}$.

Catalysts were characterized by $\mathrm{XRD}, \mathrm{H}_{2}-\mathrm{TPR}, \mathrm{CO}_{2}-\mathrm{TPD}$, low-temperature $\mathrm{N}_{2}$ sorption, and TEM. X-ray diffraction (XRD) were performed after calcination, with reduction at the post-reaction stage.

XRD patterns were obtained using a Panalytical Empyrean ((Malvern Panalytical B.V., Almelo, The Netherlands), diffractometer equipped with $\mathrm{CuK} \alpha(\lambda=1.5406 \AA)$ radiation, working in Bragg-Brentano $\theta-\theta$ geometry. Data was collected within a $2 \theta$ range of 3-90 deg. $\mathrm{Ni}$ crystallite size was calculated with Scherrer's equation, with a correction related to 
the instrument broadening included. Textural properties of the catalysts, specific surface area, and total pore volume were obtained via low-temperature nitrogen sorption. The measurements were carried out on Belsorp Mini II apparatus (BEL Japan, Inc., Osaka, Japan). The samples were outgassed for $2 \mathrm{~h}$ at $350{ }^{\circ} \mathrm{C}$ beforehand. Both temperatureprogrammed reduction $\left(\mathrm{H}_{2}-\mathrm{TPR}\right)$ and temperature-programmed desorption $\left(\mathrm{CO}_{2}-\mathrm{TPD}\right)$ profiles were obtained using a BELCAT-M instrument equipped with a TCD detector (BEL Japan, Inc., Osaka, Japan). Prior to TPR, the calcined sample was outgassed for $2 \mathrm{~h}$ at $100{ }^{\circ} \mathrm{C}$ and then reduced at the heating ramp of $10^{\circ} \mathrm{C} / \mathrm{min}$, from 100 to $900{ }^{\circ} \mathrm{C}$ with a gas mixture containing $5 \% \mathrm{H}_{2}$ in Ar. TPD was carried on the reduced sample, which was first degassed for $2 \mathrm{~h}$ at $500{ }^{\circ} \mathrm{C}$ and then cooled to $80^{\circ} \mathrm{C}$. After the pretreatment, a mixture of $10 \% \mathrm{CO}_{2} / \mathrm{He}$ was fed for $1 \mathrm{~h}$ in order to adsorb $\mathrm{CO}_{2}$ on the sample, and then pure He was flowed over the sample for $15 \mathrm{~min}$ to remove weakly adsorbed carbon dioxide. The temperature range of TPD measurements was from 100 to $800{ }^{\circ} \mathrm{C}$ with a heating rate of $10^{\circ} \mathrm{C} / \mathrm{min}$. Thermogravimetric analysis (TGA) was performed on TA Q5000 IR thermobalance (TA Instruments, Warsaw, Poland), in the temperature range from 30 to $800^{\circ} \mathrm{C}$. In a typical experiment, ca. $30-45 \mathrm{mg}$ of the material was placed on the $\mathrm{Pt}$ holder and equilibrated at $30^{\circ} \mathrm{C}$ for several minutes. A heating rate of $10^{\circ} \mathrm{C} \mathrm{min}-1$ was used, with $100 \mathrm{ml} \cdot \mathrm{min}^{-1}$ synthetic air flow provided in the direct vicinity of the sample. A buoyancy effect was found to be negligible.

Transition Electron Microscopy (TEM) was performed on a probe corrected JEOL JEM ARM-200F (NeoARM) (JEOL, Gmbh, Freising, Germany) equipped with a cold FEG gun operated at $200 \mathrm{keV}$. EDS spectra were collected by two SDD detectors covering $1.7 \mathrm{sr}$.

A catalytic test was performed inside a tubular fixed-bed quartz U-type reactor heated by the vertical electric furnace. A K-type thermocouple was placed outside the catalytic bed to control the temperature. The inlet gas composition was $\mathrm{CO}_{2} / \mathrm{H}_{2} / \mathrm{Ar}=1.5 / 6 / 2.5$ with a flow of $100 \mathrm{ml} / \mathrm{min}\left(\mathrm{GHSV}=12,000 \mathrm{~h}^{-1}\right)$. The products of the reaction such as $\mathrm{CO}_{2}$, $\mathrm{CO}, \mathrm{CH}_{4}$, and $\mathrm{H}_{2}$, were analyzed with an online micro-chromatograph (Varian GC4900) (Agilent Technologies France, Les Ulis, France) equipped with a thermal conductivity detector (TCD). The tests were carried out in the temperature range from $250{ }^{\circ} \mathrm{C}$ to $450{ }^{\circ} \mathrm{C}$, with the sample kept for $30 \mathrm{~min}$ at each temperature to obtain the steady state. The heating rate between steps was $10{ }^{\circ} \mathrm{C} / \mathrm{min}$. Materials were reduced for $1 \mathrm{~h}$ at $900{ }^{\circ} \mathrm{C}$ in $5 \% \mathrm{H}_{2} / \mathrm{Ar}$, before the reaction. The stability test was performed at $300{ }^{\circ} \mathrm{C}$ for $5 \mathrm{~h}$, under similar experimental conditions.

$\mathrm{CO}_{2}$ conversion and $\mathrm{CH}_{4}$ selectivity were calculated using the Equations (3) and (4):

$$
\begin{aligned}
& \mathrm{CO}_{2} \text { conversion as } \chi_{\mathrm{CO}_{2}}(\%)=\frac{\mathrm{F}_{\mathrm{CO}_{2} \text { inlet }}-\mathrm{F}_{\mathrm{CO}_{2} \text { outlet }}}{\mathrm{F}_{\mathrm{CO}_{2} \text { inlet }}} \cdot 100, \\
& \mathrm{CH}_{4} \text { selectivity as } \mathrm{S}_{\mathrm{CH}_{4}}(\%)=\frac{\mathrm{F}_{\mathrm{CH}_{4} \text { outlet }}}{\mathrm{F}_{\mathrm{CH}_{4} \text { outlet }}+\mathrm{F}_{\mathrm{CO} \text { outlet }}} \cdot 100,
\end{aligned}
$$

where $\mathrm{F}$ is the flow calculated from the concentration of the gases.

\section{Conclusions}

The study on vanadium promotion on hydrotalcite-derived $\mathrm{Ni}-\mathrm{Mg}-\mathrm{Al}$ catalyst for $\mathrm{CO}_{2}$ methanation confirmes that vanadium plays a role both as a textural and electronic promoter. The addition of $\mathrm{V}$ significantly changes the surface properties, such as specific surface area, mesoporosity, and also improves nickel dispersion. On the other hand, the addition of increased amounts of vanadium decreases catalytic activity, lowers selectivity to methane, and leads to the promotion of the reverse water-gas shift reaction. Vanadium additionally strongly influences the surface basicity, increasing the number of basic sites detected on the surface, with increasing V content in the samples. Finally, the V-promoted catalysts prepared by co-precipitation exhibited higher basicity and specific surface area, depending on the V-loading. The co-precipitation method resulted in the formation of an uniform hydrotalcite structure, which was later decomposed into mixed oxides during 
calcination. This homogeneous matrix of mixed oxides appared to lead to a better distribution of nickel on the surface, an enhanced basicity, and a larger specific surface area during the reduction and subsequent reaction. For comparison, nickel oxide was deposited as a separate phase on Mg-Al-V hydrotalcites in the impregnated materials. This resulted in a lower specific surface area, lower basicity (most likely due to the blockage of Mg-O sites) and ultimately comparable $\mathrm{Ni}^{\circ}$ crystallite size on the surface.

Supplementary Materials: The following are available online, Figure S1: $\mathrm{H}_{2}$-TPR profiles of the calcined V-Mg-Al hydrotalcite-derived supports, Figure S2: Low-temperature N2 sorption isotherms for calcined hydrotalcites, Figure S3: EDX for reduced Ni-CP-V2.0, Figure S4: EDX for reduced Ni-CP-V4.0, Figure S5: EDX for spent Ni-CP-V1.0, Figure S6: EDX for spent Ni-CP-V2.0.

Author Contributions: Conceptualization, P.D.C., P.S.; methodology, P.D.C.; validation, P.D.C., K.Ś., P.S.; formal analysis, P.D.C., K.Ś., P.S.; investigation, P.S., K.Ś., D.W.; I.A.; resources, P.D.C.; writing—original draft preparation, P.D.C., K.S.., P.S.; writing—review and editing, P.D.C., K.Ś., P.S., I.A., M.R.; visualization, P.D.C., M.M.; supervision, P.D.C., M.R.; project administration, P.D.C.; funding acquisition, P.D.C., M.R., M.M. All authors have read and agreed to the published version of the manuscript.

Funding: This research received no external funding.

Institutional Review Board Statement: Not applicable.

Informed Consent Statement: Not applicable.

Data Availability Statement: Data is contained within the article.

Acknowledgments: The Swiss National Science Foundation (SNF) is kindly acknowledged for cofunding of the electron microscope (R'Equip Project 206021_177020). Paulina Summa would like to kindly acknowledge The French Embassy in Poland for providing the scholarship. Katarzyna Świrk is MSCA-IF researcher at the Norwegian University of Science and Technology in Norway. This project has received funding from the European Union's Horizon 2020 research and innovation programme under the Marie Skłodowska-Curie grant agreement No 892571.

Conflicts of Interest: The authors declare no conflict of interest.

Sample Availability: Catalysts samples are available at Institut Jean Le Rond d'Alembert.

\section{References}

1. Karmalkar, A.V.; Bradley, R.S. Consequences of global warming of $1.5^{\circ} \mathrm{C}$ and $2{ }^{\circ} \mathrm{C}$ for regional temperature and precipitation changes in the contiguous United States. PLoS ONE 2017, 12, e0168697. [CrossRef] [PubMed]

2. Hughes, L. Biological consequences of global warming: Is the signal already apparent? Trends Ecol. Evol. $2000,15,56-61$. [CrossRef]

3. Matthews, T.K.R.; Wilby, R.L.; Murphy, C. Communicating the deadly consequences of global warming for human heat stress. Proc. Natl. Acad. Sci. USA 2017, 114, 3861-3866. [CrossRef] [PubMed]

4. European Commission. Stepping up Europe's 2030 climate ambition Investing in a climate-neutral future for the benefit of our people. J. Chem. Inf. Model. 2020, 53, 1689-1699.

5. Rissman, J.; Bataille, C.; Masanet, E.; Aden, N.; Morrow, W.R.; Zhou, N.; Elliott, N.; Dell, R.; Heeren, N.; Huckestein, B.; et al. Technologies and policies to decarbonize global industry: Review and assessment of mitigation drivers through 2070. Appl. Energy 2020, 266, 114848. [CrossRef]

6. Alper, E.; Yuksel Orhan, O. $\mathrm{CO}_{2}$ utilization: Developments in conversion processes. Petroleum 2017, 3, 109-126. [CrossRef]

7. Wierzbicki, D.; Motak, M.; Grzybek, T.; Gálvez, M.E.; Da Costa, P. The influence of lanthanum incorporation method on the performance of nickel-containing hydrotalcite-derived catalysts in $\mathrm{CO}_{2}$ methanation reaction. Catal. Today 2018, 307, $205-211$. [CrossRef]

8. Sreedhar, I.; Varun, Y.; Singh, S.A.; Venugopal, A.; Reddy, B.M. Developmental trends in $\mathrm{CO}_{2}$ methanation using various catalysts. Catal. Sci. Technol. 2019, 9, 4478-4504. [CrossRef]

9. Kuznecova, I.; Gusca, J. Property based ranking of $\mathrm{CO}$ and $\mathrm{CO}_{2}$ methanation catalysts. Energy Procedia 2017, 128, 255-260. [CrossRef]

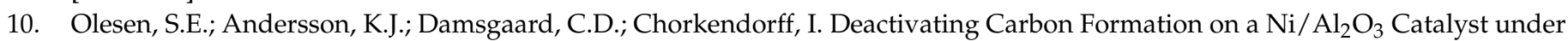
Methanation Conditions. J. Phys. Chem. C 2017, 121, 15556-15564. [CrossRef] 
11. Wierzbicki, D.; Baran, R.; Dębek, R.; Motak, M.; Grzybek, T.; Gálvez, M.E.; Da Costa, P. The influence of nickel content on the performance of hydrotalcite-derived catalysts in $\mathrm{CO}_{2}$ methanation reaction. Int. J. Hydrogen Energy 2017, 42, 23548-23555. [CrossRef]

12. Liu, Q.; Gu, F.; Zhong, Z.; Xu, G.; Su, F. V-promoted Ni/ $\mathrm{Al}_{2} \mathrm{O}_{3}$ catalyst for synthetic natural gas (SNG) production: Catalyst preparation methodologies. Korean J. Chem. Eng. 2016, 33, 1599-1605. [CrossRef]

13. Cavani, F.; Trifiro, F.; Vaccari, A. Hydrotalcite-type anionic clays: Preparation, properties and applications. Catal. Today 1991, 11, 173-301. [CrossRef]

14. Prinetto, F.; Ghiotti, G.; Das, N.; Tichit, D.; Coq, B. Characterisation of palladium catalysts supported on hydrotalcite-derived mixed oxides. In Oxide-Based Systems at the Crossroads of Chemistry; Gamba, A., Colella, C., Coluccia, S., Eds.; Studies in Surface Science and Catalysis; Elsevier: Amsterdam, The Netherlands, 2001; Volume 140, pp. 391-400.

15. Wang, S.; Pan, Q.; Peng, J.; Sun, T.; Gao, D.; Wang, S. $\mathrm{CO}_{2}$ methanation on Ni/Ce $\mathrm{C}_{0.5} \mathrm{Zr}_{0.5} \mathrm{O}_{2}$ catalysts for the production of synthetic natural gas. Fuel Process. Technol. 2014, 123, 166-171. [CrossRef]

16. Ma, S.; Tan, Y.; Han, Y. Methanation of syngas over coral reef-like Ni/ $\mathrm{Al}_{2} \mathrm{O}_{3}$ catalysts. J. Nat. Gas Chem. 2011, 20, 435-440. [CrossRef]

17. Dębek, R.; Radlik, M.; Motak, M.; Galvez, M.E.; Turek, W.; Da Costa, P.; Grzybek, T. Ni-containing Ce-promoted hydrotalcite derived materials as catalysts for methane reforming with carbon dioxide at low temperature-On the effect of basicity. Catal. Today 2015, 257, 59-65. [CrossRef]

18. Summa, P.; Samojeden, B.; Motak, M.; Wierzbicki, D.; Alxneit, I.; Świerczek, K.; Da Costa, P. Investigation of Cu promotion effect on hydrotalcite-based nickel catalyst for $\mathrm{CO}_{2}$ methanation. Catal. Today 2021. [CrossRef]

19. Bahari, M.B.; Nguyen, T.D.; Singh, S.; Siang, T.J.; Shafiqah, M.N.N.; Jun, L.N.; Phuong, P.T.T.; Ainirazali, N.; Vo, D.V.N. Catalytic performance of yttrium-doped co/mesoporous alumina catalysts for methane dry reforming. AIP Conf. Proc. 2019, 2124. [CrossRef]

20. Tsiotsias, A.I.; Charisiou, N.D.; Yentekakis, I.V.; Goula, M.A. Bimetallic ni-based catalysts for $\mathrm{CO}_{2}$ methanation: A review. Nanomaterials 2021, 11, 28. [CrossRef]

21. Wierzbicki, D.; Debek, R.; Motak, M.; Grzybek, T.; Gálvez, M.E.; Da Costa, P. Novel Ni-La-hydrotalcite derived catalysts for $\mathrm{CO}_{2}$ methanation. Catal. Commun. 2016, 83, 5-8. [CrossRef]

22. Wierzbicki, D.; Baran, R.; Dębek, R.; Motak, M.; Gálvez, M.E.; Grzybek, T.; Da Costa, P.; Glatzel, P. Examination of the influence of La promotion on $\mathrm{Ni}$ state in hydrotalcite-derived catalysts under $\mathrm{CO}_{2}$ methanation reaction conditions: Operando X-ray absorption and emission spectroscopy investigation. Appl. Catal. B Environ. 2018, 232, 409-419. [CrossRef]

23. Maluf, S.S.; Assaf, E.M. Ni catalysts with Mo promoter for methane steam reforming. Fuel 2009, 88, 1547-1553. [CrossRef]

24. Xu, L.; Lian, X.; Chen, M.; Cui, Y.; Wang, F.; Li, W.; Huang, B. $\mathrm{CO}_{2}$ methanation over Co-Ni bimetal-doped ordered mesoporous $\mathrm{Al}_{2} \mathrm{O}_{3}$ catalysts with enhanced low-temperature activities. Int. J. Hydrogen Energy 2018, 43, 17172-17184. [CrossRef]

25. Cao, H.X.; Zhang, J.; Guo, C.L.; Chen, J.G.; Ren, X.K. Modifying surface properties of KIT-6 zeolite with Ni and V for enhancing catalytic CO methanation. Appl. Surf. Sci. 2017, 426, 40-49. [CrossRef]

26. Carabineiro, S.A.; Brás Fernandes, F.; Ramos, A.M.; Vital, J.; Silva, I.F. Vanadium as a catalyst for $\mathrm{NO}_{2} \mathrm{~N}_{2} \mathrm{O}$ and $\mathrm{CO}_{2}$ reaction with activated carbon. Catal. Today 2000, 57, 305-312. [CrossRef]

27. Shahul Hamid, M.Y.; Abdul Jalil, A.; Abdul Rahman, A.F.; Tuan Abdullah, T.A. Enhanced reactive $\mathrm{CO}_{2}$ species formation: Via $\mathrm{V}_{2} \mathrm{O}_{5}$-promoted Ni/KCC-1 for low temperature activation of $\mathrm{CO}_{2}$ methanation. React. Chem. Eng. 2019, 4, 1126-1135. [CrossRef]

28. Lu, X.; Gu, F.; Liu, Q.; Gao, J.; Liu, Y.; Li, H.; Jia, L.; Xu, G.; Zhong, Z.; Su, F. VOx promoted Ni catalysts supported on the modified bentonite for $\mathrm{CO}$ and $\mathrm{CO}_{2}$ methanation. Fuel Process. Technol. 2015, 135, 34-46. [CrossRef]

29. Cao, H.; Wang, W.; Cui, T.; Wang, H.; Zhu, G.; Ren, X. Enhancing $\mathrm{CO}_{2}$ hydrogenation to methane by ni-based catalyst with v species using 3d-mesoporous kit-6 as support. Energies 2020, 13, 2235. [CrossRef]

30. Dula, R.; Wcislo, K.; Stoch, J.; Grzybowska, B.; Serwicka, E.M.; Kooli, F.; Bahranowski, K.; Gawel, A. Layered double hydroxidederived vanadium catalysts for oxidative dehydrogenation of propane: Influence of interlayer-doping versus layer-doping. Appl. Catal. A Gen. 2002, 230, 281-291. [CrossRef]

31. Bahranowski, K.; Dula, R.; Kooli, F.; Serwicka, E.M. ESR study of the thermal decomposition of V-containing layered double hydroxides. Colloids Surfaces A Physicochem. Eng. Asp. 1999, 158, 129-136. [CrossRef]

32. Świrk, K.; Summa, P.; Wierzbicki, D.; Motak, M.; Da Costa, P. Vanadium promoted Ni(Mg,Al)O hydrotalcite-derived catalysts for $\mathrm{CO}_{2}$ methanation. Int. J. Hydrogen Energy 2021, 46, 17776-17783. [CrossRef]

33. Le, T.A.; Kim, J.; Kang, J.K.; Park, E.D. $\mathrm{CO}$ and $\mathrm{CO}_{2}$ methanation over $\mathrm{M}(\mathrm{M}=\mathrm{Mn}, \mathrm{Ce}, \mathrm{Zr}, \mathrm{Mg}, \mathrm{K}, \mathrm{Zn}$, or V)-promoted $\mathrm{Ni} / \mathrm{Al} @ \mathrm{Al}_{2} \mathrm{O}_{3}$ catalysts. Catal. Today 2020, 348, 80-88. [CrossRef]

34. Dębek, R.; Motak, M.; Galvez, M.E.; Grzybek, T.; Da Costa, P. Influence of Ce/Zr molar ratio on catalytic performance of hydrotalcite-derived catalysts at low temperature $\mathrm{CO}_{2}$ methane reforming. Int. J. Hydrogen Energy 2017, 42, 23556-23567. [CrossRef]

35. Meira, D.M.; Cortez, G.G.; Monteiro, W.R.; Rodrigues, J.A.J. Vanadium oxides supported on hydrotalcite-type precursors: The effect of acid-base properties on the oxidation of isopropanol. Braz. J. Chem. Eng. 2006, 23, 351-358. [CrossRef]

36. Garbarino, G.; Kowalik, P.; Riani, P.; Antoniak-Jurak, K.; Pieta, P.; Lewalska-Graczyk, A.; Lisowski, W.; Nowakowski, R.; Busca, G.; Pieta, I.S. Improvement of $\mathrm{Ni} / \mathrm{Al}_{2} \mathrm{O}_{3}$ catalysts for low-temperature $\mathrm{CO}_{2}$ methanation by vanadium and calcium oxide addition. Ind. Eng. Chem. Res. 2021, 60, 6554-6564. [CrossRef] 
37. Alothman, Z.A. A review: Fundamental aspects of silicate mesoporous materials. Materials 2012, 5, 2874. [CrossRef]

38. Wierzbicki, D.; Moreno, M.V.; Ognier, S.; Motak, M.; Grzybek, T.; Da Costa, P.; Gálvez, M.E. Ni-Fe layered double hydroxide derived catalysts for non-plasma and DBD plasma-assisted CO2 methanation. Int. J. Hydrogen Energy 2020, 45, 10423-10432. [CrossRef]

39. Sukkathanyawat, H.; Tungkamani, S.; Phongaksorn, M.; Rattana, T.; Narataruksa, P.; Yoosuk, B. Promoter Effect on the Physicochemical Properties of Cobalt Based Catalyst for CO Hydrogenation. Energy Procedia 2015, 79, 372-377. [CrossRef]

40. Valcheva-Traykova, M.L.; Davidova, N.P.; Weiss, A.H. Thermal decomposition of Mg, Al-hydrotalcite material. J. Mater. Sci. 1993, 28, 2157-2162. [CrossRef]

41. Chmielarz, L.; Rutkowska, M.; Kuśtrowski, P.; Drozdek, M.; Piwowarska, Z.; Dudek, B.; Dziembaj, R.; Michalik, M. An influence of thermal treatment conditions of hydrotalcite-like materials on their catalytic activity in the process of $\mathrm{N}_{2} \mathrm{O}$ decomposition. $J$. Therm. Anal. Calorim. 2011, 105, 161-170. [CrossRef]

42. Świrk, K.; Gálvez, M.E.; Motak, M.; Grzybek, T.; Rønning, M.; Da Costa, P. Yttrium promoted Ni-based double-layered hydroxides for dry methane reforming. J. CO2 Util. 2018, 27, 247-258. [CrossRef]

43. Aziz, M.A.A.; Jalil, A.A.; Wongsakulphasatch, S.; Vo, D.V.N. Understanding the role of surface basic sites of catalysts in $\mathrm{CO}_{2}$ activation in dry reforming of methane: A short review. Catal. Sci. Technol. 2020, 10, 35-45. [CrossRef]

44. Alxneit, I. Particle Size Distributions from Electron Microscopy Images: Avoiding Pitfalls. J. Phys. Chem. A 2020, 24, 10075-10081. [CrossRef]

45. Liu, Q.; Gu, F.; Lu, X.; Liu, Y.; Li, H.; Zhong, Z.; Xu, G.; Su, F. Enhanced catalytic performances of $\mathrm{Ni} / \mathrm{Al}_{2} \mathrm{O}_{3}$ catalyst via addition of $\mathrm{V}_{2} \mathrm{O}_{3}$ for $\mathrm{CO}$ methanation. Appl. Catal. A Gen. 2014, 488, 37-47. [CrossRef]

46. Guil-Lopez, R.; Navarro, R.M.; Ismail, A.A.; Al-Sayari, S.A.; Fierro, J.L.G. Influence of Ni environment on the reactivity of $\mathrm{Ni}-\mathrm{Mg}$-Al catalysts for the acetone steam reforming reaction. Int. J. Hydrogen Energy 2015, 40, 5289-5296. [CrossRef]

47. Shen, Y.; Ge, M.; Lua, A.C. Deactivation of bimetallic nickel-copper alloy catalysts in thermocatalytic decomposition of methane. Catal. Sci. Technol. 2018, 8, 3853-3862. [CrossRef]

48. Reimnitz, L.C.; Lwin, T.; Lopez, M.; Milliron, D.J. Oxygen storage in transition metal-doped bixbyite vanadium sesquioxide nanocrystals. ChemRxiv 2020, 3, 9645-9651. [CrossRef] 